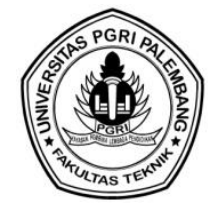

\title{
ANALISIS PERENCANAAN BRONJONG SUNGAI DESA MUARA BARU OGAN KOMERING ILIR
}

\author{
Amiwarti $^{*}$, Eko Nopriansyah ${ }^{2}$ \\ ${ }^{12}$ Prodi Teknik Sipil Fakultas Teknik Universitas PGRI Palembang \\ *Corresponding Author, Email : amiwartiishak@gmail.com
}

\begin{abstract}
ABSTRAK
Gerusan air pada dinding-dinding sungai akan menyebabkan terjadinya kelongsoran pada dinding sungai terlebih jika dinding sungai lumayan tinggi dan sudut lereng terlalu curam. Longsoran tersebut harus segera ditanggulangi secepatnya agar tanah di pinggiran sungai tidak hilang percuma. Stabilitas lereng dan perencanaan pembangunan bronjong sebagai salah satu solusi dari permasalahan ini. Angka keamanan terhadap kohesi, sudut geser, dan sudut lereng sebagai tolok ukur stabilitas lereng. Dengan menggunakan metode Fellenius didapat Angka keamanan yang kesemuanya dibawah 1,2 dan dinyatakan tidak aman. Maka solusinya adalah dengan melandaikan lereng yang awalnya $70^{\circ}$ menjadi $39^{\circ}$, serta ketinggian lereng yang sebelumnya 5,38 meter menjadi 2,4 meter. Hingga Fs terhadap kohesi, sudut geser, dan sudut lereng mengalami kenaikan yang cukup signifikan. Fs terhadap kohesi dan sudut geser yang awalnya hanya sebesar 0,78 dapat menjadi 1,21 dan dinyatakan aman. Begitu juga angka Fs terhadap sudut lereng yang awalnya sebesar 0,318 dapat menjadi 1,2 dan dinyatakan aman. Hingga dengan kata lain bronjong layak dibangun dengan tinggi 2,4 meter dan sudut $39^{\circ}$. Adapun volume keseluruhan bronjong yang direncanakan dalam studi ini adalah $6250 \mathrm{~m}^{3}$.
\end{abstract}

Kata Kunci : Bronjong, Longsor, Fellenius.

\section{PENDAHULUAN}

Sungai yang mengalir memiliki kecepatan dan debit air yang berbeda-beda. Kecepatan dan debit air ini sedikit banyak akan mempengaruhi bentuk aliran yang dilaluinya. Gerusan air pada dinding-dinding sungai akan menyebabkan erosi yang juga terkadang mengakibatkan longsoran dinding sungai terlebih jika dinding sungai tersebut lumayan tinggi. Fenomena ini hampir terjadi di setiap Daerah Aliran Sungai (DAS) dan pada akhirnya mengakibatkan beberapa masalah, diantaranya berkurangnya tanah warga di pedesaan karena longsoran tanah warga yang jatuh ke sungai dan cekungan sungai yang terus melebar hingga masuk ke pemukiman warga. Sangat jelas hal ini harus segera dicarikan solusinya.

Permasalahan ini juga terjadi di pinggiran sungai desa Muara Baru Kabupaten Ogan Komering Ilir (OKI) Propinsi Sumatera Selatan. Salah satu solusi yang ditawarkan adalah perencanaan pembangunan Bronjong sebagai penahan tanah agar tidak lagi terjadi longsoran tanah serta menahan kecepatan laju aliran sungai yang dapat menahan benturan air langsung terhadap tanah di lereng tersebut. Menurut Ariyani, N, Stabilitas dinding Penahan Tanah dipengaruhi olehtekanan tanah lateral,aliran air dan stabilitas daya dukung tanah pondasi pada dinding penahan tanah. Gaya-gaya penahan berupa gaya gesekan/ geseran, lekatan, (dari kohesi), kekuatan geser tanah, dan lain sebagainya. Sehingga kita harus memeriksa apakah ada permukaan gelincir yang dapat menggerakkan lereng tersebut, cara tersebut kita sebut analisa stabilitas lereng. (Canonica, L,1991 : 23). Untuk menghitung tekanan tanah aktif dibelakang dinding penahan tanah dapat digunakan rumus rankine, menurut Braja M, (1984:15) adalah :

$$
\begin{aligned}
& \mathrm{K}_{\mathrm{a}}=\tan ^{2}(45-\Phi 2) \\
& \mathrm{P}_{\mathrm{a}}=1 / 2 \mathrm{~K}_{\mathrm{a}} \gamma \mathrm{H}^{2}
\end{aligned}
$$


Menurut Sunggono,KH. (1998 : 12), lereng dapat digolongkan menjadi dua tipe, yaitu: Lereng Tak Terhingga atau Tak Terbatas dan Lereng Terbatas.

Menurut Bowles,dkk ( 2004 : 32) dalam Buku "Sifat-sifat Fisis dan Geoteknis Tanah (Mekanika Tanah), Tanah adalah campuran partikel-partikel yang terdiri dari salah satu atau seluruh jenis berikut ini:

1. Berangkal (boulders), potongan batuan yang besar, biasanya lebih besar dari 250 sampai 300 $\mathrm{mm}$. Untuk kisaran ukuran 150 sampai $250 \mathrm{~mm}$, fragmen batuan ini disebut kerakal (cobbles) atau pebbles.

2. Kerikil (gravel), partikel batuan yang berukuran 5 sampai $150 \mathrm{~mm}$.

3. Pasir (sand), partikel batuan yang berukuran 0,074 sampai $5 \mathrm{~mm}$. Berkisar dari kasar (3 sampai $5 \mathrm{~mm})$ sampai halus $(<1 \mathrm{~mm})$

4. Lanau (silt), partikel batuan yang berukuran dari 0,002 sampai 0,074 $\mathrm{mm}$. Lanau dalam jumlah besar ditemukan dalam defosit yang disedimentasikan ke dalam danau atau dekat garis pantai pada muara sungai.

5. Lempung (clay), partikel mineral yang berukuran lebih kecil dari 0,002 mm. Partikel-partikel ini merupakan sumber utama dari kohesi pada tanah yang "kohesif".

6. Koloid (colloids), partikel mineral yang "diam”. Berukuran lebih kecil dari 0,001 mm.

\section{Komposisi Tanah}

Menurut Bowles, dkk, (2004:32) Tanah adalah campuran partikel-partikel yang terdiri dari salah satu atau seluruh jenis berikut ini:

1. Berangkal (boulders), potongan batuan yang besar, biasanya lebih besar dari 250 sampai 300 $\mathrm{mm}$. Untuk kisaran ukuran 150 sampai $250 \mathrm{~mm}$, fragmen batuan ini disebut kerakal (cobbles) atau pebbles.

2. Kerikil (gravel), partikel batuan yang berukuran 5 sampai $150 \mathrm{~mm}$.

3. Pasir (sand), partikel batuan yang berukuran 0,074 sampai $5 \mathrm{~mm}$. Berkisar dari kasar (3 sampai $5 \mathrm{~mm}$ ) sampai halus ( $<1 \mathrm{~mm})$

4. Lanau (silt), partikel batuan yang berukuran dari 0,002 sampai 0,074 mm. Lanau dalam jumlah besar ditemukan dalam defosit yang disedimentasikan ke dalam danau atau dekat garis pantai pada muara sungai.

5. Lempung (clay), partikel mineral yang berukuran lebih kecil dari 0,002 mm. Partikel-partikel ini merupakan sumber utama dari kohesi pada tanah yang "kohesif".

6. Koloid (colloids), partikel mineral yang "diam". Berukuran lebih kecil dari 0,001 mm.

Adapun istilah-istilah terkait dengan tanah adalah sebagai berikut:

Angka pori (void ratio) e didefinisikan sebagai

$\mathrm{e}=\frac{V_{v}}{V_{S}}$

Porositas (porosity) $\mathrm{n}$ didefinisikan sebagai

$\mathrm{n}=\frac{V_{v}}{V_{s}} \times 100$

porositas sering dinyatakan dalam persentase, walaupun dipakai dalam perhitungan teknis sebagai desimal.

Kadar air (water content) w didefinisikan sebagai

$\mathrm{w}=\frac{W_{w}}{W_{S}} \times 100$

Derajat kejenuhan (degree of saturation) S didefinisikan sebagai

$\mathrm{S}=\frac{V_{w}}{V_{v}} \times 100$ 
Berat jenis (spesific gravity) G. Terdapat dua definisi berat jenis yang dapat dipakai.

$\mathrm{G}=\frac{\text { berat volume satuan suatu material }}{\text { berat volume satuan air pada } 4^{\circ} \mathrm{C}}$

\section{METODE PENELITIAN}

Metode Penelitian menggambarkan bagaimana suatu penelitian ditempuh dari awal hingga akhir penelitian, Sigit, S, (1999 : 6). Penelitian ini lebih bersifat ekperimental, menurut Arikunto, (1998 : 17), penelitian ekperimental adalah penelitian yang dilakukan terhadap variable masa yang akan datang, variable yang sesungguhnya belum terjadi tetapi sengaja diadakan dalam bentuk perlakuan coba-coba yang terjadi dalam eksperimen.

Tahapan dalam penelitian ini meliputi :

Data Primer berupa :

- Gambar titik lokasi penelitian

- Survey Lapangan, antara lain: ketinggian lereng, panjang lokasi rencana, jenis tanah, dan lain sebagainya.

- Informasi dari masyarakat, antara lain ketinggian maksimal dan minimal permukaan sungai beberapa tahun ke belakang.

Data Skunder berupa :

- Peta Topografi sungai Desa Muara Baru Kabupaten Ogan Komering Ilir (OKI)

- Peta Aliran Sungai Desa Muara Baru Kabupaten Ogan Komering Ilir (OKI)

- Data-data sekunder juga didapat dari literatur jurnal dan diskusi dengan pembimbing

Survey Lapangan, untuk mengamati/mempelajari kondisi lapangan dan menentukan ukuran dan ketinggian tanah, kemudian menganalisis data dengan menggunakan rumus untuk menentukan porositas,kadar air, derajat kejenuhyan yang merupakan faktor pendukung untuk menentukan :

- Tinggi kritis lereng

- Tekanan Tanah Aktif dan Pasif

- Gaya yang timbul pada bronjong

- Tekanan (E bronjong dan Desain Bronjong)

- Volume total keseluruhan

Menentukan Kesimpulan

\section{HASIL DAN PEMBAHASAN}

\section{Angka Keamanan FS}

Fs Terhadap Kohesi (C) Dan Sudut Geser (Ф), Tinjauan $25^{\circ}, 20^{\circ}, 15^{\circ}, 10^{\circ}$

$$
\begin{aligned}
& \Phi=30^{\circ} \quad \mathrm{F} \Phi=\frac{\tan \Phi}{\tan \Phi d} \quad=\frac{\tan 30^{\circ}}{\tan 30^{\circ}} \quad=1 \\
& \mathrm{Fc}=\frac{C}{C d} \quad=\frac{0,535}{0,535} \quad=1 \\
& \Phi \quad=25^{\circ} \quad \mathrm{F} \Phi=\frac{\tan \Phi}{\tan \Phi d} \quad=\frac{\tan 30^{\circ}}{\tan 25^{\circ}} \quad=1,238 \\
& \mathrm{Fc}=\frac{C}{C d} \quad=\frac{0,535}{1,211} \quad=0,442 \\
& \Phi=20^{\circ} \quad \mathrm{F} \Phi=\frac{\tan \Phi}{\tan \Phi d} \quad=\frac{\tan 30^{\circ}}{\tan 20^{\circ}} \quad=1,586 \\
& \mathrm{Fc}=\frac{C}{C d} \quad=\frac{0,535}{1,4526} \quad=0,37
\end{aligned}
$$




$$
\begin{aligned}
& \Phi \quad=15^{\circ} \quad \mathrm{F} \Phi=\frac{\tan \Phi}{\tan \Phi d} \quad=\frac{\tan 30^{\circ}}{\tan 15^{\circ}} \quad=2,155 \\
& \mathrm{Fc}=\frac{C}{C d} \quad=\frac{0,535}{1,695} \quad=0,316 \\
& \Phi \quad=10^{\circ} \quad \mathrm{F} \Phi=\frac{\tan \Phi}{\tan \Phi d} \quad=\frac{\tan 30^{\circ}}{\tan 10^{\circ}} \quad=3,274 \\
& \mathrm{Fc}=\frac{C}{C d} \quad=\frac{0,535}{1,937} \quad=0,276
\end{aligned}
$$

Karena Fs terhadap Kohesi (Fc) dan Sudut Geser (FФ) didapat 0,78 $\geq 1$ (Tidak Aman), maka di cari dahulu ketinggian kritis lereng.

\section{Tinggi Kritis Lereng}

$$
\begin{aligned}
\mathrm{C}=0,535 \text { ton } / \mathrm{m}^{2} & \gamma=2,25 \text { ton } / \mathrm{m}^{3} \\
\mathrm{~m} & =\frac{C}{\gamma \times H c r} \\
\mathrm{Hcr} & =\frac{C}{\gamma \times \mathrm{m}} \\
& =\frac{0,535}{2,25 \times 0,05} \\
& =2,378 \mathrm{~m}=2,4 \mathrm{~m}
\end{aligned}
$$

Fs Terhadap Sudut Lereng (F⿱)

$$
\begin{aligned}
\text { Luas Penampang } 10 & =(0,5 \times 1,5) / 2 \\
\text { Luas Penampang } 2 & =(4,35 \times 1)-((1 \times 0,1) / 2)-((2,85 \times 1) / 2) \\
& =4,35-0,05-1,425 \\
& =2,875 \mathrm{~m}^{2} \\
& =((4,25+1,05) .1)-((1 \times 0,35) / 2)-((1,05 \times 0,7) \\
& =5,3-0,175-0,18375 \\
& =4,942 \mathrm{~m}^{2} \\
& =(1 \times 5)-((1 \times 0,5) / 2) \\
& =5-0,25 \\
\text { Luas Penampang Penampang } 4 & =4,750 \mathrm{~m}^{2} \\
\text { Luas Penampang 5 } & =(4,5 \times 1)-((1 \times 0,75) / 2) \\
& =4,5-0,375 \\
& =4,125 \mathrm{~m}^{2} \\
\text { Luas Penampang 6 } & =(3,75 \times 1)-((1 \times 0,9) / 2) \\
& =3,75-0,45 \\
& =3,3 \mathrm{~m}^{2} \\
\text { Luas Penampang } 7 & =((2,85 \times 1) / 2) \\
& =1,425 \mathrm{~m}^{2}
\end{aligned}
$$

$\mathrm{F} \Theta \quad=\frac{c L+W \cos \theta \tan \Phi}{W \sin \theta}$

$\sum \mathrm{L} \quad=\frac{\emptyset}{360^{\circ}} \times 2$ Л $\mathrm{R}$

$\sum \mathrm{L} \quad=\frac{84^{\circ}}{360^{\circ}} \times 2 \times 3,14 \times 6,3 \mathrm{~m}$

$$
=9,232 \mathrm{~m}
$$

$\mathrm{W}=$ Luas Penampang $\mathrm{x} \gamma$ 
Dari data tanah didapat nilai $\gamma \mathrm{sat}=22,00 \mathrm{kN} / \mathrm{m}^{3}=2,2433752$ ton $\mathrm{c}=5,25 \mathrm{kN} / \mathrm{m}^{2}=0,535$ ton

Maka didapat:

$$
\begin{aligned}
& \mathrm{W} 1=0,375 \times 2,2433752=0,841 \\
& \mathrm{~W} 2=2,875 \times 2,2433752=6,450 \\
& \mathrm{~W} 3 \quad=4,942 \times 2,2433752=11,085 \\
& \text { W4 }=4,750 \times 2,2433752=10,656 \\
& \text { W5 }=4,125 \times 2,2433752=9,254 \\
& \text { W6 }=3,3 \times 2,2433752=7,403 \\
& \text { W7 }=1,425 \times 2,2433752=3,197
\end{aligned}
$$

Dari konversi Fs keseluruhan = 0,318 (Tidak Aman), Agar Fs menjadi 1,2 (Aman), maka

$$
\text { Ns } \quad \begin{aligned}
& =\frac{c}{F K \times \gamma \text { sat } x h} \\
& =\frac{0,535}{1,2 \times 2,2433752 \times 5,38} \\
& =0,037
\end{aligned}
$$

Jadi, agar Fs menjadi 1,2 dan lereng dinyatakan stabil maka sudut lereng $(\theta)$ diubah menjadi $39^{\circ}$

\section{Tekanan Tanah Aktif dan Pasif (Ea dan Ep)}

Koefisien tekanan tanah

$$
\begin{aligned}
\lambda & =\tan ^{2}(45-\Phi / 2) \\
& =\tan ^{2}(45-30 / 2) \\
& =\tan ^{2}(45-15) \\
& =\tan ^{2} 30 \\
& =0,34
\end{aligned}
$$

Tekanan tanah akibat beban atas $\left(q=10 \mathrm{~N} / \mathrm{m}^{2}=1,02 \mathrm{ton} / \mathrm{m}^{2}\right)$

$$
\begin{aligned}
\text { Ea1 } & =\lambda \times \mathrm{q} \times \mathrm{H} \\
& =0,34 \times 1,02 \times 5,38 \\
& =1,87 \text { ton }
\end{aligned}
$$

Tekanan Tanah Kohesi

$$
\begin{aligned}
\mathrm{Ea} 2 & =\frac{P h}{P v}=\frac{1}{N \Phi}-\frac{2 c}{P v \sqrt{N \Phi}} \\
\mathrm{Pv} & =\gamma \times \mathrm{H} \\
& =2,2433752 \times 5,38 \\
& =12,07 \text { ton } \\
\mathrm{Ph} \quad & =\frac{P v}{N \Phi}-\frac{2 c}{\sqrt{N \Phi}} \\
& =\frac{12,07}{\tan (45-(30: 2))}-\frac{2(0,535)}{\sqrt{\tan (45-30: 2))}} \\
& =\frac{12,07}{\tan 30}-\frac{1,07}{\sqrt{\tan 30}} \\
& =\frac{12,07}{0,58}-\frac{1,07}{0,76} \\
& =\frac{9,1732-0,6206}{0,4408}
\end{aligned}
$$


Akibat Air

$$
\begin{aligned}
& =\frac{8,5526}{0,4408} \\
& =19,403 \text { ton }
\end{aligned}
$$

$$
\begin{aligned}
\text { Ep } & =1 / 2 \times \text { yair } \times \text { Hair } \times \text { air } \\
& =1 / 2 \times 1 \times 4 \times 1 \\
& =2 \text { ton }
\end{aligned}
$$

\section{Menghitung Besarnya Gaya Yang Timbul Pada Bronjong (Ra)}

$$
\begin{aligned}
& \sum \mathrm{H}=0 \\
& =-\mathrm{Ra}+\mathrm{Ea} 1+\mathrm{Ea} 2-\mathrm{Ep} \\
& =-\mathrm{Ra}+1,87+19,403-2 \\
& =-\mathrm{Ra}+19,273 \\
& -\mathrm{Ra}=-19,273 \\
& \mathrm{Ra} \quad=19,273 \text { ton }
\end{aligned}
$$

\section{Tekanan (Ebronjong) Dan Desain Bronjong}

Ebronjong $\geq \mathrm{Ra}$

Ebronjong $=$ Ukuran Bronjong $\times \gamma$ batu kali $x$ jumlah bronjong (Ukuran Bronjong $\mathrm{x}$ ybatu kali $\mathrm{x}$ jumlah bronjong) $\geq \mathrm{Ra}$ $(2 \times 1 \times 0,5) \times 2,55 \times$ jumlah bronjong $\geq 19,273$

$$
\begin{aligned}
\text { Jumlah Bronjong } & \geq \frac{19,273}{1 \times 2,55} \\
& \geq 7,558 \\
& \geq 8 \text { Bronjong }
\end{aligned}
$$

Volume Keseluruhan Bronjong (Panjang $=1500$ Meter)

\begin{tabular}{|c|c|c|c|}
\hline LT. 1 & $2 \times 0,5 \times 1500$ & $=$ & \multicolumn{1}{|c|}{1500} \\
\hline LT. 2 & $2 \times 0,5 \times 1500$ & $=$ & 1500 \\
\hline LT.3 & $2 \times 0,5 \times 1500$ & $=$ & 1500 \\
\hline LT. 4 & $2 \times 0,5 \times 1500$ & $=$ & 1500 \\
\hline LT.5 & $1 \times 0,5 \times 1500$ & $=$ & 750 \\
\hline \multicolumn{3}{|c|}{ Total } & $\mathbf{6 7 5 0} \mathbf{M 3}$ \\
\hline
\end{tabular}

\section{KESIMPULAN}

1. Nilai Fs terhadap kohesi $(C)$ dan sudut geser $(\Phi)$ dengan sudut lereng $70^{\circ}$ adalah 0,78 $\geq 1$ (tidak aman).

Sebagai solusi dari hal ini adalah tinggi lereng diturunkan yang awalnya adalah 5,38 meter menjadi 2,4 meter hingga nilai Fs yang awalnya $0,78 \geq 1$ (tidak aman) menjadi $1,21 \geq 1$ (aman). Dengan kata lain Fs terhadap kohesi (C) dan sudut geser ( $\Phi)$ mengalami kenaikan sebesar $\pm 55,13 \%$

2. Nilai Fs terhadap sudut lereng yang sudut awalnya adalah $70^{\circ}$ didapat angka keamanan sebesar $0,318 \geq 1$ (tidak aman). 
Sebagai solusi dari hal ini adalah sudut lereng dibuat lebih landai yang awalnya $70^{\circ}$ menjadi $39^{\circ}$, hingga nilai Fs yang awalnya $0,318 \geq 1$ (tidak aman) menjadi $1,2 \geq 1$ (aman).

3. Bronjong layak dibangun dengan tinggi 2,4 meter dan sudut bronjong $39^{\circ}$.

4. Volume keseluruhan bronjong yang digunakan adalah sebesar $6750 \mathrm{~m}^{3}$.

\section{DAFTAR PUSTAKA}

Arikunto, Suharsini,2007, Prosedur Penelitian Suatu Pendekatan Praktek,Rineka Cipta, Jakarta.

Ariyani, N, http://www,e-jurnal.ukrimuversity.ac.id.

Bowles, Joseph.E, Johan K. Hainim. 2004, Sifat-Sifat Fisis dan Geoteknis Tanah (Mekanika Tanah). Erlangga. Jakarta.

Canonica, Lucio. 1991, 2007. Memahami Mekanika Tanah. Angkasa, Bandung.

Das, Braja,M,1984.Mekanika Tanah jilid 2. Erlangga.Jakarta

Sigit, Soehardi, 2005, Pengantar Metodologi Penelitian.

Sunggono, Kh, 1998. Mekanika Tanah. Nova. Bandung.

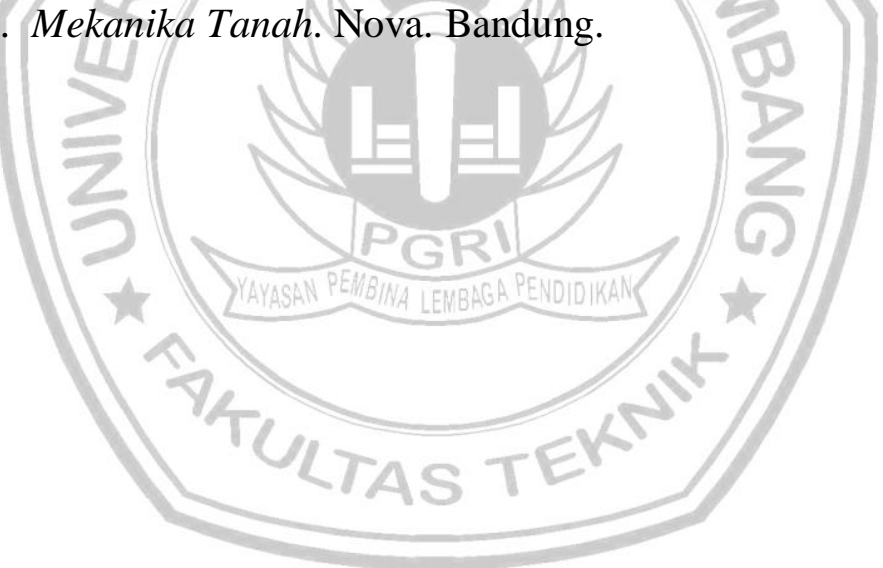

